\title{
Endovascular visual verification of anastomotic patency in coronary bypass
}

\author{
Wael Hassanein, MD, ${ }^{a}$ Amr Saleh, MS, ${ }^{a}$ Emad A. Magdy, MD, ${ }^{b}$ and Mostafa Abdelrahman, MS ${ }^{a}$ \\ Alexandria, Egypt
}

\footnotetext{
From the ${ }^{a}$ Cardiothoracic Surgery Department, Faculty of Medicine, Alexandria, Egypt; and the

${ }^{\mathrm{b}}$ Otorhinolaryngology-Head \& Neck Surgery Department, Faculty of Medicine, Alexandria, Egypt.

No funding was received for this work.

Disclosures: Authors have nothing to disclose with regard to commercial support.

Received for publication May 26, 2018; revisions received July 18, 2018; accepted for publication July 26, 2018; available ahead of print Oct 23, 2018.

Address for reprints: Wael Hassanein, MD, Cardiothoracic Surgery Department, Faculty of Medicine, 21521 Alexandria, Egypt (E-mail: waelhassanein@yahoo.com).

J Thorac Cardiovasc Surg 2019;157:e183-5

$0022-5223 / \$ 36.00$

Copyright (C) 2018 by The American Association for Thoracic Surgery

https://doi.org/10.1016/j.jtcvs.2018.07.105
}

- Video clip is available online.

According to the European Society of Cardiology and European Association for Cardio-Thoracic Surgery guidelines on myocardial revascularization, routine intraoperative flow measurement should be considered (class IIa, level of evidence C). ${ }^{1}$ Flow measurement has well-known limitations, however, especially its low positive predictive value. ${ }^{2}$ When there are unsatisfactory flow measurements, it is not always easy to differentiate between technical and nontechnical reasons, and assessment of graft patency with flow measurement alone may prompt unnecessary revision of the anastomosis.

Intraoperative angiography is cumbersome and not always feasible. Fluorescence imaging can be more accurate than flow measurement, ${ }^{3}$ but it also has limitations, especially with obtuse marginal grafts and subepicardial anastomoses.

We present our experience with a straightforward way to assess the anastomotic quality: direct endovascular visualization. When used routinely, this method can exclude the anastomotic quality as a cause for any suboptimal finding.

\section{TECHNIQUE}

After approval of the institutional ethical committee, patient consent was obtained for the "out of indication" use of a video-assisted 1.3-mm semiflexible sialendoscope to assess the coronary anastomotic quality intraoperatively (Marchal Sialendoscope; Karl Storz, Tuttlingen, Germany). In addition, consent was obtained to use any remaining unused piece of the great saphenous vein to perform an intentionally erroneous anastomosis in vitro.

\section{DISCUSSION}

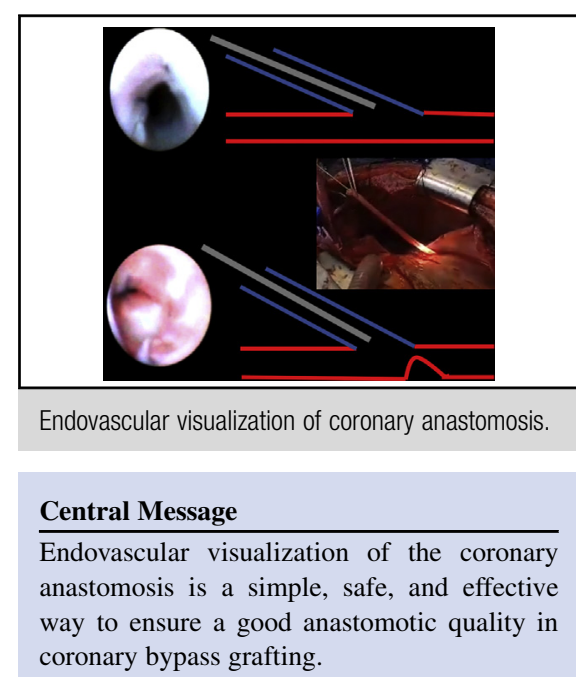

See Commentary page e187.

After the coronary anastomosis had been performed, the endoscope was introduced through the free graft to visualize the anastomosis from inside (Figure 1 and Video 1). In case of in situ left internal thoracic artery, we could introduce the endoscope through an opening in the artery made for anastomosing the right internal thoracic artery as a $\mathrm{T}$ graft. It is also possible to assess the distal anastomosis by introducing the scope into the coronary artery before placing the last suture.

Continuous irrigation with bubble-free crystalloid cardioplegia or normal saline solution is essential for visualization. With a $20-\mathrm{mL}$ syringe, irrigation can be done through the irrigation port or working port or through a cannula introduced into the graft beside the scope.

At the end of the operation, a remaining piece of vein was used to perform an end-to-side anastomosis with a suture intentionally taking the back wall (Figure 2).

Operative and postoperative data are shown in Table 1.

Endovascular visualization of the coronary anastomosis is a simple and effective way to ensure a good anastomotic quality in coronary bypass grafting. It can be used routinely in almost all cases, and the results can be saved electronically. The technique is especially useful for junior surgeons during their training. 


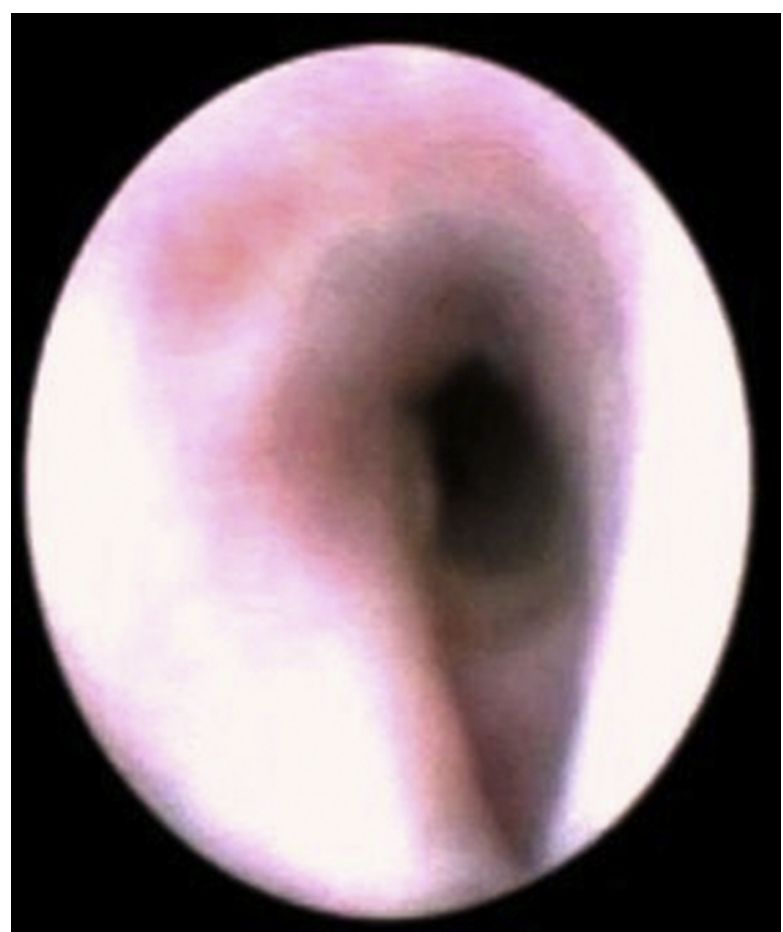

FIGURE 1. Saphenous vein graft to coronary artery anastomosis.

Although the idea is old, ${ }^{4-6}$ it has not gained wide popularity. With recent advances in technology, however, the imaging quality has become much better than it was decades ago. We therefore expect that endovascular visualization of coronary anastomosis will be revived and gain in popularity.

We have no concerns regarding the safety of this technique. The scope is even safer than coronary probes, because it is introduced under vision and, with saline irrigation, does not touch the vessel walls. In addition, its bright tip is easily seen from outside (Figure 2).

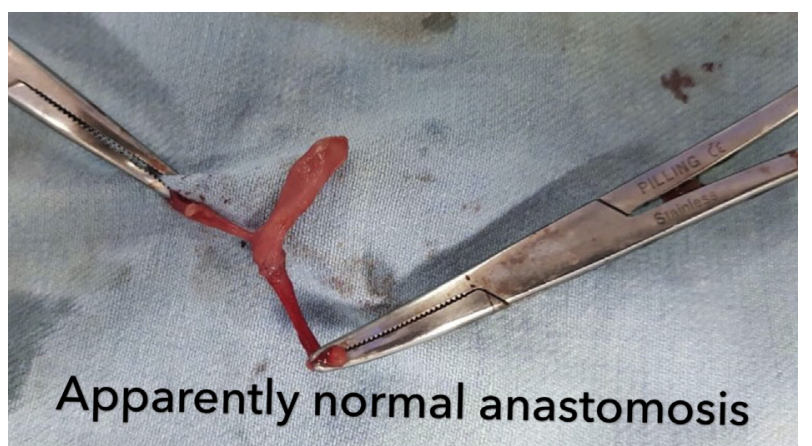

VIDEO 1. Endovascular visualization of the saphenous vein, anastomosis, and coronary artery. $R S V G$, Right saphenous vein graft; $O M$, obtuse marginal coronary artery. Video available at: https://www.jtcvs.org/ article/S0022-5223(18)32468-1/fulltext.

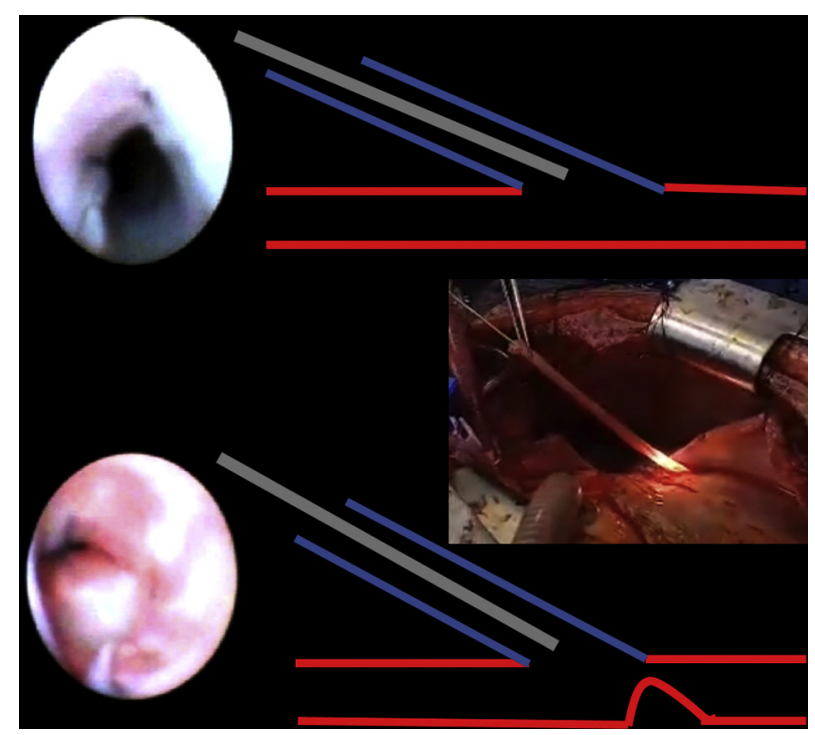

FIGURE 2. The scope introduced into a vein graft, with diagrams showing patent and erroneous anastomoses and their corresponding angioscopic views.

An important limitation of this scope is its relative rigidity. When used with fragile grafts, great caution is needed. With limited flexibility, it is very difficult to examine the proximal anastomosis (before placing the last suture), and it is impossible to advance the scope further to detect twists or kinks.

Although still not perfect, the images are adequate to judge the quality of the anastomosis. Large studies are needed,

\section{TABLE 1. Operative and postoperative data}

\begin{tabular}{|c|c|}
\hline $\begin{array}{l}\text { No. of patients (isolated on-pump coronary bypass } \\
\text { grafting) }\end{array}$ & 17 \\
\hline Examined saphenous vein grafts & 31 \\
\hline Examined right internal thoracic artery grafts & 3 \\
\hline $\begin{array}{l}\text { Examined left internal thoracic arteries through } \\
\text { openings for } \mathrm{T} \text { grafts }\end{array}$ & 3 \\
\hline Failed adequate visualization of the anastomosis* & 0 \\
\hline $\begin{array}{l}\text { Fragile right internal thoracic arteries (no attempt to } \\
\text { introduce the scope) }\end{array}$ & 4 \\
\hline $\begin{array}{l}\text { Fragile left internal thoracic arteries (no attempt to } \\
\text { introduce the scope) }\end{array}$ & 4 \\
\hline $\begin{array}{l}\text { Revised grafts on the basis of flow measurements or } \\
\text { endovascular visualization } \dagger\end{array}$ & 0 \\
\hline $\begin{array}{l}\text { Complications caused by the scope or endothelial } \\
\text { injury }\end{array}$ & 0 \\
\hline Mortality or major complications & 0 \\
\hline Patients who needed postoperative angiography & 0 \\
\hline
\end{tabular}


however, to determine the sensitivity and specificity of the technique to detect minor anastomotic errors.

We thank Professor Wahid Etman, the surgeon-in-chief, for his support.

\section{References}

1. Authors/Task Force members, Windecker S, Kolh P, Alfonso F, Collet JP, Cremer J, Falk V, et al. 2014 ESC/EACT guidelines on myocardial revascularization: The Task Force on Myocardial Revascularization of the European Society of Cardiology (ESC) and the European Association for Cardio-Thoracic Surgery (EACTS) Developed with the special contribution of the European Association of Percutaneous Cardiovascular Interventions (EAPCI). Eur Heart J. 2014;35: 2541-619.
2. Tokuda Y, Song M, Ueda Y, Usui A, Akita T. Predicting early coronary artery bypass graft failure by intraoperative transit time flow measurement. Ann Thorac Surg. 2007;84:1928-33.

3. Desai ND, Miwa S, Kodama D, Koyama T, Cohen G, Pelletier MP, et al. A randomized comparison of intraoperative indocyanine green angiography and transit-time flow measurement to detect technical errors in coronary bypass grafts. J Thorac Cardiovasc Surg. 2006;132:585-94.

4. Sanborn TA, Rygaard JA, Westbrook BM, Lazar HL, McCormick JR, Roberts AJ. Intraoperative angioscopy of saphenous vein and coronary arteries. J Thorac Cardiovasc Surg. 1986;91:339-43.

5. Chaux A, Lee ME, Blanche C, Kass RM, Sherman TC, Hickey AE, et al Intraoperative coronary angioscopy. technique and results in the initial 58 patients. J Thorac Cardiovasc Surg. 1986:92:972-6.

6. Bessou JP, Melki J, Bouchart F, Mouton-Schleifer D, Tabley A, Arrignon J, et al. Intraoperative coronary angioscopy - technique and results: a study of 38 patients. J Card Surg. 1993;8:483-7. 